\title{
TERRITÓRIO USADO EM UNIDADE DE CONSERVAÇÃO: UMA VISÃO DA DINÂMICA TERRITORIAL E DOS CONFLITOS SOCIOAMBIENTAIS NO PARQUE ESTADUAL DOS PIRINEUS, GOIÁS
}

\author{
Edna Araújo Andrade \\ Pontifícia Universidade Católica de Goiás, Escola de Gestão e Negócios, Goiânia, GO, Brasil \\ ednaaraujo@pucgoias.edu.com \\ Ivanilton José de Oliveira \\ Pós-Graduação em Geografia, Instituto de Estudos Socioambientais, Goiânia, GO, Brasil \\ Universidade Federal de Goiás - UFG \\ oliveira@ufg.br
}

\begin{abstract}
RESUMO
O estudo aborda os usos do território do Parque Estadual dos Pirineus, em Goiás. Com base no entendimento do território como realidade cuja complexidade envolve as dimensões socioespaciais, assume-se que as possibilidades de recorte analítico são diversas. Considerando esse pressuposto, as dimensões política e relacional são enfatizadas na análise, com a finalidade de consubstanciar uma abordagem integrada a partir da categoria de território usada. Para tanto, foi realizada pesquisa documental em fontes públicas e foram aplicadas entrevistas com os sujeitos relacionados diretamente à delimitação ou afetados pela instalação do parque. Os resultados apontam para um panorama problemático, envolvendo conflitos socioambientais, e indicam as situações de poder que têm prevalecido e interferido na dinâmica territorial, a despeito das normas de restrições estabelecidas pelo Sistema Nacional de Unidades de Conservação (SNUC).
\end{abstract}

Palavras-chave: Unidade de conservação. Território usado. Conflitos socioambientais. Dinâmica territorial.

\section{USED TERRITORY IN CONSERVATION UNIT: A VISION OF TERRITORIAL DYNAMICS AND SOCIO-ENVIRONMENTAL CONFLICTS IN PIRINEUS STATE PARK, GOIÁS}

\begin{abstract}
The study discusses the uses of the territory of Pirineus State Park, in the state of Goiás, Brazil. Understanding that the territory is a reality whose complexity involves the sociospatial dimensions, it is assumed that the possibilities of analytical approach are diverse. Taking into account this premise, the political and relational dimensions are emphasized in the analysis, with the purpose to substantiate an integrated approach, from the 'used territory' category. As main methodological procedures, documentary research was carried out in public sources and interviews were applied with the subjects directly related to the delimitation or affected by the installation of the park. The results indicate a problematic panorama, involving socioenvironmental conflicts, and demonstrate the power situations that have prevailed and interfered in the territorial dynamics, in spite of the norms of restrictions established by the National System of Conservation Units (SNUC, in acronym in Portuguese).
\end{abstract}

Keywords: Conservation unit. Used territory. Socioenvironmental conflicts. Territorial dynamics.

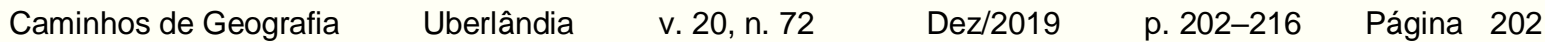




\section{INTRODUÇÃO}

Este trabalho aborda o uso do território e os conflitos socioambientais no âmbito das unidades de conservação. Parte-se do entendimento de que a análise do território, compreendendo o processo de apropriação do espaço por meio das relações de poder, associadas, dentre outras, às vertentes políticas, econômicas e sociais, contém embasamentos explicativos da realidade Complementarmente, a categoria território contribui com importante marco teórico referente ao conteúdo relacional e comporta uma base sólida para a compreensão dessas unidades como recortes territoriais no contexto da política ambiental correlata, bem como dos diversos atores envolvidos.

Assim, o ponto central da discussão sobre a categoria território na perspectiva aqui delineada admite que o território, modernamente, é entendido não apenas como limite político-administrativo que tem o Estado como ator hegemônico do poder, mas como espaço efetivamente usado pela sociedade.

O Sistema Nacional de Unidades de Conservação (SNUC) propicia uma análise dinâmica do território e de sua materialização, considerando a ideia de distintos usos nas categorias prescritas, envolvendo a preservação ou a conservação, estratégias que englobam a proteção ambiental. A proteção integral, que inclui os Parques, proporciona uma maior restrição ao uso, disciplinando sobre pesquisa científica, atividades de educação ambiental, recreação e turismo ecológico e visitação pública (BRASIL, 2000, art. 8-13).

Evidencia-se, então, na delimitação de unidade de conservação, um tipo de poder: o de natureza política, no sentido restrito ao poder do Estado. Pela própria criação de limites, se caracteriza como uma forma de controle sobre as pessoas e os recursos presentes nesse espaço. Esse novo recorte legitima a identificação dos grupos sociais já existentes. Assim, emergem outras formas de poder e de relações entre esses grupos (HAESBAERT, 2009).

Nessa ótica, as unidades de conservação podem ser entendidas como territórios apropriados pelo poder estatal com o objetivo de controlar o uso dos recursos naturais ali distribuídos e de disciplinar o manejo do espaço por meio do controle das atividades humanas exercidas sobre ele. Como aponta Vargas (2007), as áreas protegidas vêm se consolidando, de modo geral, enquanto tema de investigação científica, principalmente por estarem inerentemente associadas à geração de conflitos envolvendo populações humanas e o uso do território.

Essas pesquisas têm analisado e investigado os limites dos fundamentos teóricos e práticas de gestão que orientam as tomadas de decisão nas unidades de conservação, indicando uma mudança de foco sobre a forma como as relações entre a sociedade e a natureza têm sido abordadas no âmbito das UC, de maneira a estabelecer uma visão politizada dessa realidade.

Nessa concepção, o presente estudo contempla a dinâmica no uso do território do Parque Estadual dos Pirineus. Com esse enfoque, toma-se como fio condutor a teoria espacial de Milton Santos, por considerar sua utilidade e contemporaneidade para as análises pertinentes ao tema e ao objeto de pesquisa. As argumentações são encadeadas a partir da análise da categoria território usado, proposta pelo autor, considerando, sobretudo, sua fundamentação na dimensão social do espaço.

O Parque Estadual dos Pirineus (Pepi), gerido pela Secretaria do Meio Ambiente, Recursos Hídricos, Infraestrutura, Cidades e Assuntos Metropolitanos (Secima), foi a segunda UC de proteção integral criada em Goiás, no ano de 1987 - antes havia somente o Parque da Serra de Caldas Novas -, por meio da Lei Estadual no 10.321, de 20/11/1987, regulamentada pelo Decreto oㅜ 4.830, de 12/10/1997.

A unidade de conservação foi delimitada com 2.833 hectares e está localizada nos municípios de Pirenópolis, Cocalzinho e Corumbá de Goiás (Figura 1). Conforme o Decreto supracitado, o parque tem como objetivo "preservar a fauna, a flora e os mananciais ali existentes, protegendo sítios naturais de excepcional beleza" (GOIÁS, 1997), bem como preservar as fitofisionomias que lá ocorrem: Cerrado Sentido Restrito, Cerrado Rupestre, Campo Limpo, Mata Seca e Mata de Galeria.

\begin{tabular}{|c|c|}
\hline Caminhos de Geografia & Uberlândia \\
\hline
\end{tabular}


Em sua área encontra-se um importante marco geográfico, o segundo maciço mais elevado do estado de Goiás, o Pico dos Pirineus, com 1.380 metros de altitude, que engloba um dos diversos divisores das bacias hidrográficas dos rios Tocantins e Paraná.

Figura 1 - Mapa de localização do PEPI.

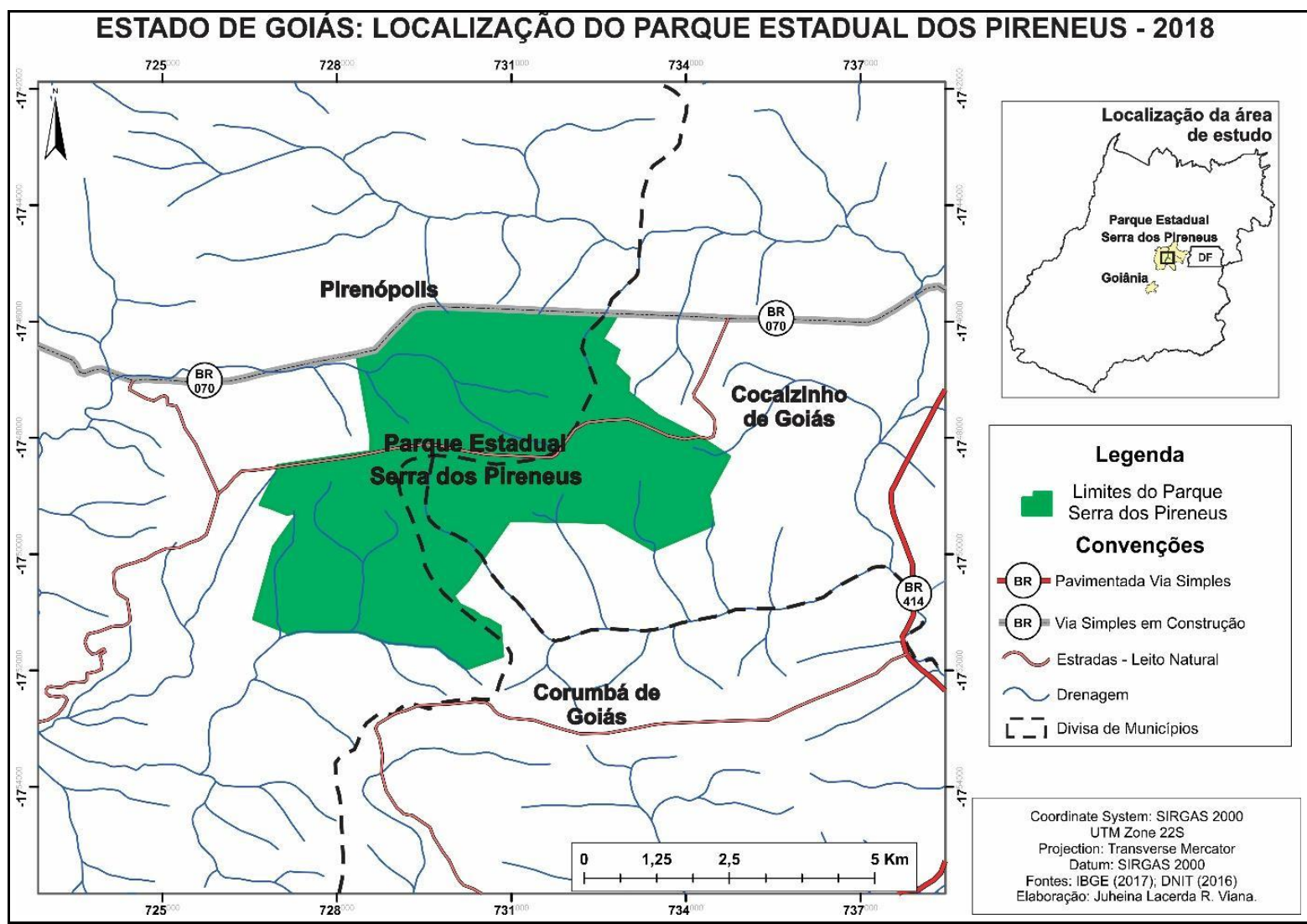

O parque apresenta-se vulnerável à degradação de seus ambientes e da pouca infraestrutura lá construída, em função das atividades folclóricas, religiosas e turísticas praticadas dentro de seus limites, e pela inexistência de fiscalização permanente. Pela proximidade com grandes cidades como Brasília (150 km) e Goiânia (130 km) -, a Serra dos Pirineus e seu entorno têm sido sujeitos a uma crescente pressão antrópica, que leva à substituição das paisagens naturais por outros usos do solo. A degradação do ambiente também é preocupante devido, principalmente, às atividades de mineração, como a extração de quartzitos, localmente denominados de "pedra de Pirenópolis" (BOSQUETI, 2008).

A regularização fundiária do Pepi foi totalmente concluída, mas ainda existem proprietários que alegam não terem recebido o valor indenizatório até o presente momento, configurando litígios judiciais que perduram desde a sua criação.

O plano de manejo foi elaborado em 2003, mas, como o produto apresentado pela empresa responsável não estava de acordo com as normas contratuais, acabou não sendo aceito, o que fez com que até o momento a situação não tenha sido resolvida. O território do parque não está totalmente cercado e a facilidade de acesso e demanda significativa pelos recursos naturais existentes no seu interior são os fatores que mais contribuem para a vulnerabilidade da gestão da UC. De acordo com a avaliação da eficácia de gestão, realizada por Andrade (2012), e a Avaliação Rápida da Priorização da Gestão (RAPPAM), aplicada pelo World Wildlife Fund for Nature - WWF, em 2014, dentre os 12 (doze) parques estaduais existentes em Goiás, o Pepi está entre as unidades 
mais vulneráveis em relação à facilidade de acesso às áreas dos parques e atividades agropastoris realizadas no entorno (GOIÁS, 2014).

Essas situações, dentre outras, denotam o contexto que envolve este estudo, que teve como objetivo identificar e interpretar o conjunto de ações dos atores sociais que definem a dinâmica, o uso do território e os conflitos socioambientais relacionados ao Parque dos Pirineus.

\section{METODOLOGIA}

A pesquisa tem caráter qualitativo e como tal pode ser caracterizada pela tentativa de empreender uma compreensão detalhada dos significados e características situacionais. A natureza qualitativa se consubstancia no seu objetivo fundamental, conforme a indicação de Richardson (1999, p. 102), que "não reside na produção de opiniões representativas e objetivamente mensuráveis de um grupo; [e sim] no aprofundamento da compreensão de um fenômeno social por meio de entrevistas em profundidade e análises qualitativas da consciência articulada dos atores envolvidos no fenômeno".

Os procedimentos metodológicos compreenderam, inicialmente, uma pesquisa bibliográfica exploratória, realizada em indexadores de periódicos (como Scopus, Latindex e Google Acadêmico) e no Catálogo de Teses e Dissertações da Capes (http://catalogodeteses.capes.gov.br/catalogo-teses), para aprofundamento teórico nas temáticas de unidades de conservação, território e conflitos socioambientais, a partir das publicações realizadas em formato de artigos científicos, livros, teses e dissertações.

Essa etapa foi procedida por uma investigação documental sobre a legislação e os documentos normativos, gerenciais e operacionais da Secima, identificando os principais atores que participaram do processo de criação das unidades e da definição de seu recorte espacial, bem como daqueles que influenciaram ou ainda estão envolvidos nos usos do território.

As técnicas adotadas envolveram a análise exploratória e o inventário da legislação e documentos normativos, gerenciais e operacionais da Secima; seguidos de sua organização de acordo com as respectivas fontes. Foram utilizadas as seguintes fontes secundárias: leis, decretos estaduais e outros documentos de criação e delimitação da unidade de conservação; processos de regularização fundiária; relatórios de fiscalizações realizadas nos parques; processos judiciais sobre o uso do território e conflitos correspondentes.

Essas análises foram complementadas com coleta de dados primários, a partir da aplicação de entrevistas semiestruturadas, baseadas em roteiros específicos. Os trabalhos de campo foram realizados em julho e setembro de 2016, e agosto e novembro de 2017 , envolvendo trinta e quatro sujeitos entrevistados, sendo dez proprietários que foram desapropriados e doze proprietários/moradores dentro dos limites da zona de amortecimento. Considerando que a maior área do Pepi abrange o município de Pirenópolis, foram selecionadas oito propriedades neste, duas no município de Cocalzinho e uma no município de Corumbá.

Para esses procedimentos foram considerados os limites do parque e sua respectiva zona de amortecimento (Figura 2), com a delimitação de uma faixa de $3 \mathrm{~km}$, indicada pela Resolução oㅡ 473/2015, de 17/12/2015, do Conselho Nacional Meio ambiente (Conama). A identificação da amostra foi consubstanciada no Cadastro Ambiental Rural (CAR), com base em dados extraídos em março de 2016. O CAR, criado pela Lei oㅜ 2.651, de 25/05/2012, é um registro eletrônico, obrigatório para todos os imóveis rurais, formando base de dados estratégica para o controle, o monitoramento e o combate ao desmatamento das florestas e demais formas de vegetação nativa do Brasil, além do planejamento ambiental e econômico dos imóveis rurais.

Foram entrevistados, também, sete gestores e coordenadores da Secima e cinco monitores que trabalham diretamente no Parque.

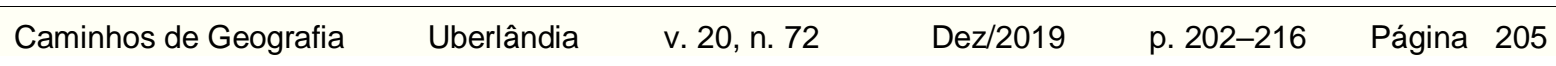


Figura 2 - Mapa das propriedades rurais na zona de amortecimento do Pepi (2016).

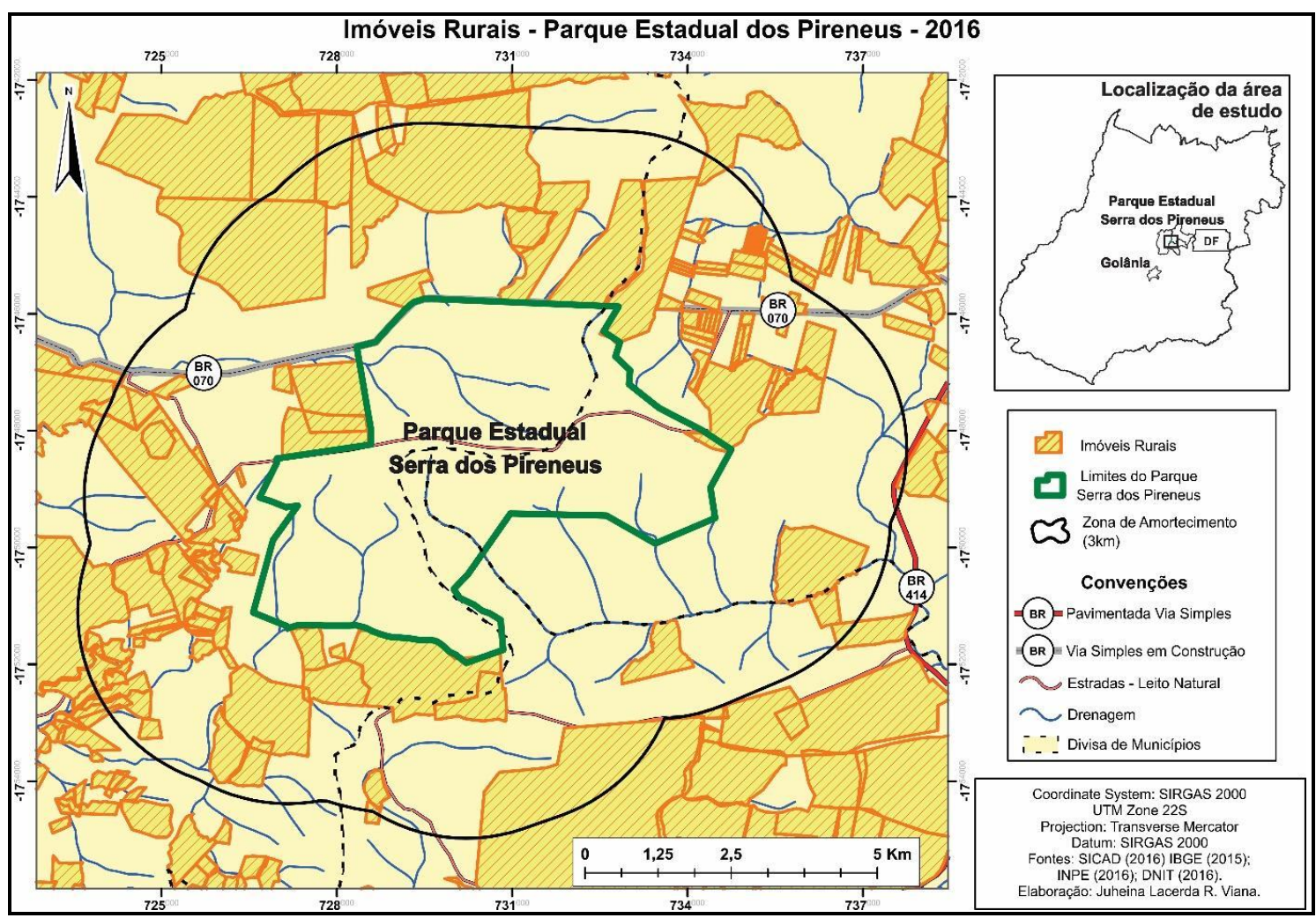

\section{MARCO TEÓRICO}

Numa visão contextualizada, as análises realizadas remetem ao aspecto amplo e multiescalar inerente ao atual período, de cunho universal. A unicidade das técnicas, do tempo, a convergência dos momentos e a unicidade do motor da vida econômica e social, com a emergência de uma maisvalia na escala global, enunciada por Santos (2003), conduz a geografia ao desafio de repensar o território.

Na síntese feita por Moraes (2013), o conceito de território possuía, nos seus escritos iniciais, uma percepção essencialmente demarcatória, isto é, de designação de unidades político-administrativas. Milton Santos acrescenta mais conteúdo e densidade a esse conceito, atribuindo ao território qualidades como a de compartimento do espaço definido pelo domínio estatal; espaço de circulação de fluxos materiais e imateriais; dimensão historicamente constituída; totalidade e unidade de análise geográfica; fonte de identidade e condição para a reprodução da vida social; recurso e abrigo para diferentes agentes sociais; dimensão que guarda diferentes lógicas de uso e apropriação; espaço de todos os agentes sociais (MORAES, 2013; SANTOS, 1996, 2003).

No livro "O Brasil: território e sociedade no início do século XXI" (SANTOS; SILVEIRA, 2001), os autores, ao tratarem sobre o território como espaço de um país, propõem a noção de "espaço territorial", que significa a presença de um Estado, de um espaço e de uma nação (ou mais nações). Para eles, o território, "em si mesmo, não constitui uma categoria de análise ao considerarmos o espaço geográfico". A análise se daria considerando a categoria de território usado, sinônimo de espaço geográfico. Os autores assim explicam: "quando quisermos definir qualquer pedaço do território, devemos levar em conta a interdependência e a inseparabilidade entre a materialidade, que inclui a natureza, e o seu uso, que inclui a ação humana, isto é, o trabalho e a política" (SANTOS; SILVEIRA, 2001, p. 247).

O território usado inclui todos os atores, e não apenas o Estado, como na concepção herdada da modernidade; não apenas os que têm mobilidade, como na mais pura noção de espaço de fluxos; e se refere à existência total, e não apenas à noção de espaço econômico. Equivale ao espaço banal, "espaço de todos: empresas, instituições, pessoas; espaço das vivências" (SANTOS, 2008, p. 108).

Caminhos de Geografia Uberlândia $\quad$ v. 20, n. $72 \quad$ Dez/2019 $\quad$ p. 202-216 Página 206


Acrescido do conceito de espaço banal, o território usado caracteriza uma categoria de análise social que, embora complexa, possibilita a análise sistemática e permanente da constituição do território. Da forma como definido pelos autores, o território diz respeito ao espaço do país (sistemas de ações e sistemas de objetos), contudo, embora a análise do território privilegie, para Milton Santos, a escala nacional e se fixe a uma nação, a reflexão pode ser aplicada a territórios delimitados por grupos sociais em todas as escalas.

Assim, sua importante contribuição reside no fato de proporcionar a análise relacional da configuração do meio observada sob diferentes tempos históricos, bem como as possíveis ações modificadoras desse meio geográfico. Essas análises levam à constatação de que as características do território usado observado como categoria propiciam uma aproximação com a dimensão política da realidade. Ademais, a abordagem do território envolve conflitos, poder, agentes e atores. Dessa forma, o território é admitido por Milton Santos, no "rol conceitual" da Geografia, como o mais adequado para investigar o exercício de poder, porque surge sempre associado a propósitos claramente políticos (MORAES, 2013, p. 69). Não obstante o espaço também possua essa dimensão, o destaque político no território é evidenciado quando aplicado como categoria de análise.

Os agentes e atores, tidos como os sujeitos da dinâmica territorial, possuem significados próprios e correspondem a um contexto. Como explicam Steinberger e Amado (2006, p. 179), o agente é aquele que efetivamente exerce uma atividade, que ocupa e cria o território, e os atores representam os interesses em arenas de poder. Assim, "a cena do poder é ocupada pelos atores. Os agentes estão por trás, configurando os territórios, são os verdadeiros configuradores".

Nesse enfoque, Souza (2010, p. 95) define território como sendo "o campo das relações de poder espacialmente delimitadas e operando sobre um substrato referencial". Essa noção denota a compreensão do território em duas dimensões, quais sejam, a periodicidade (no tempo) e a escala (no espaço). No que diz respeito à periodicidade, os territórios podem ter tanto um caráter permanente - como nos territórios nacionais, territórios indígenas - quanto de de unidades de conservação.

A diversidade de escalas remete à visão ampla do território para um conjunto de ações, apreendendo a multiplicidade dos usos do território, compreendidos de forma articulada, em sistema, como evidencia Cataia (2011, p. 121): "as materialidades e seus usos; usos que são as ações humanas trabalhadas e politizadas".

Haesbaert (2006, p. 121) também enfatiza a existência de múltiplos territórios em diversas escalas, que são apropriados simbolicamente por grupos através da mediação de forças:

O território é o produto de uma relação desigual de forças, envolvendo o domínio, o controle político-econômico do espaço e sua apropriação simbólica, ora conjugados e mutuamente reforçados, ora desconectados e contraditoriamente articulados. Esta relação varia muito, por exemplo, conforme as classes sociais, os grupos culturais e as escalas geográficas que estivermos analisando. Como no mundo contemporâneo vive-se concomitantemente uma multiplicidade de escalas, numa simultaneidade atroz de eventos vivenciam-se também, ao mesmo tempo, múltiplos territórios.

Nessa formulação, o autor esclarece, ainda, que o território inspira a identificação (positiva) e a efetiva "apropriação". Assim, em qualquer acepção, tem a ver com poder, mas não apenas com o tradicional "poder político": diz respeito tanto ao poder no sentido mais concreto, de dominação, quanto ao poder no sentido mais simbólico, de apropriação. Lefebvre (1986) distingue apropriação de dominação ("possessão", "propriedade"), no contexto de usos do território praticados por atores diferentes. A primeira sendo um processo muito mais simbólico, carregado das marcas do "vivido", do valor de uso, o segundo mais concreto, funcional e vinculado ao valor de troca.

O uso reaparece em acentuado conflito com a troca no espaço, pois ele implica "apropriação" e não "propriedade". Ora, a própria apropriação implica tempo e tempos, um ritmo ou ritmos, símbolos e uma prática. Tanto mais o espaço é funcionalizado, tanto mais ele é dominado pelos "agentes" que o manipulam tornando-o unifuncional, menos ele se presta à apropriação. Por quê? Porque ele se coloca fora do tempo vivido, aquele dos usuários, tempo diverso e complexo. (LEFEBVRE, 1986). 
Para Hasbaert (2007), enquanto "continuum" dentro de um processo de dominação e/ou apropriação, o território e a territorialização devem ser trabalhados na multiplicidade de suas manifestações - que é também e, sobretudo, multiplicidade de poderes, neles incorporados através dos múltiplos agentes/sujeitos envolvidos. Assim, "devemos primeiramente distinguir os territórios de acordo com os sujeitos que os constroem, sejam eles indivíduos, grupos sociais, o Estado, empresas, instituições como a Igreja etc." (HASBAERT, 2007, p. 3). As razões do controle social pelo espaço variam conforme a sociedade ou a cultura, o grupo e, muitas vezes, o próprio indivíduo.

A territorialidade, por sua vez, além de incorporar uma dimensão estritamente política, diz respeito também às relações econômicas e culturais, pois está "intimamente ligada ao modo como as pessoas utilizam a terra, como elas próprias se organizam no espaço e como elas dão significado ao lugar". Como já mencionado, está inserido nessa concepção o caráter simultâneo com outras formas de territorialização. Muitas vezes, essa simultaneidade do território denota relações de conflito entre os diferentes poderes que estão (re)construindo aquele território (HAESBAERT, 2002). É nesse sentido que o autor enfatiza a "multiterritorialidade", considerada, nesse enfoque, como uma antítese da desterritorialização.

Em relação às áreas protegidas, se por um lado existe um modelo de política de unidades de conservação, do ponto de vista global, também há influências no âmbito político de estados, municípios e localidades, de acordo com os interesses para a criação de uma unidade de conservação e a escolha de sua categoria. Em qualquer dos casos, estabelecem-se relações de poder sobre uma base territorial, em que a criação de uma unidade de conservação gera um processo de desterritorialização e re-territorialização (HAESBAERT, 2010; SOUZA, 2010).

Vislumbra-se, então, a possibilidade de apreender a unidade de conservação em sua totalidade, a partir das múltiplas relações de poder e interações produzidas entre os diversos atores, variando no tempo e nas suas diversas escalas de interação e influência (desde o local até o global), de acordo com os aspectos de apropriação material e simbólica, bem como as dimensões culturais, históricas, religiosas, dentre outras que envolvem os usos do território.

Ademais, o potencial político nas estratégias de conservação e proteção ambiental nos convida a pensar nos usos do território, envolvendo agentes hegemônicos e não hegemônicos; a análise dos conflitos entre agentes e atores por meio dos elementos atribuídos ao conceito de território usado leva a questionamentos relacionados a pensar como, onde, por que e para que o território é usado (SANTOS; SILVEIRA, 2001)

Uma das principais causas de conflitos em torno dos espaços protegidos é o problema da regularização fundiária. Grande parte das unidades de conservação de proteção integral, criadas desde a época do regime militar, ainda não apresenta situação totalmente regularizada (CATTANEO, 2011).

Contudo, os problemas relacionados à desapropriação de terras privadas representam apenas uma parte dos conflitos originados com a criação de unidades de conservação. Conflitos relativos ao uso dos recursos naturais retratam a complexidade que envolve o território, tais como o potencial energético dos rios e mananciais para empreendimentos de geração de energia, insumos para a indústria madeireira, mineral (areia, carvão, minério de ferro, calcário, fosfato etc.), recursos pesqueiros e de espécies nativas para produção de cosméticos e alimentos (recursos genéticos vegetais e animais), além da apropriação paisagística pela indústria de turismo e do mercado imobiliário.

Conforme explica Acselrad (2004), os conflitos ocorrem quando são envolvidos grupos sociais com modos diferenciados de apropriação, uso e significado de território; originam-se quando pelo menos um dos grupos sofre ameaças sobre a continuidade das formas sociais de apropriação do seu meio. Essas ameaças podem acontecer por impactos indesejáveis ocorridos com o solo, a água, o ar ou os sistemas vivos, decorrentes do exercício e das práticas de outros grupos, ou seja, trata-se de conflito socioambiental.

Dessa forma, os conflitos socioambientais ocorrem em função dos embates entre grupos sociais que tem modos diferentes de se inter-relacionar com o ambiente social e natural, ou seja, surgem das interações ecológicas entre os diversos atores sociais e o meio biofísico (LITTLE, 2001).

$\begin{array}{lllll}\text { Caminhos de Geografia } & \text { Uberlândia } & \text { v. 20, n. } 72 & \text { Dez/2019 } & \text { p. 202-216 }\end{array}$ Página 208


Em especial, os estudos no campo da sociologia ambiental e da ecologia política, tais como os de Little (2001), Guivant (2002), Herculano (2002), Acselrad (2004), Guivant, Scheibe e Assmann (2005), abordam a categoria "conflitos ambientais" como meio de análise para evidenciar a mudança social. Essa abordagem representa uma clivagem teórica mais ampla, sugerindo a ampliação do foco de análise para a inclusão de todas as populações influenciadas, direta e indiretamente, pela criação de unidades de conservação.

Vargas (2007) enfatiza que os conflitos socioambientais são cada vez mais frequentes na realidade dos países da América Latina. Em parte, é consequência da debilidade na implementação das políticas e esquemas de gestão disponíveis para a regulação do uso e acesso aos recursos naturais. Devem-se considerar, também, as dinâmicas sociais e econômicas que dizem respeito aos recursos naturais, cada vez mais complexas. É comum que o Estado se encontre sem recursos técnicos, administrativos e/ou financeiros para administrar conflitos em torno do uso dos recursos naturais nos quais existem, por exemplo, grandes assimetrias de poder. É nesse sentido que os conflitos são um importante sensor das relações sociais que se mobilizam ao redor do acesso e do uso dos recursos naturais (LEFF, 1998).

Os recortes analíticos contextualmente apresentados trazem à tona, portanto, a importância dos usos do território como abertura à análise da realidade enquanto totalidade, propiciando os elementos básicos para a discussão sobre a dinâmica e o uso do território do Parque dos Pirineus, tratados a seguir.

\section{RESULTADOS E DISCUSSÃO}

São remotas as propostas de preservação da região dos Pirineus, com primeiros registros em 1880, época da procura pelo ouro em terras goianas. A história retrata uma série de acontecimentos envolvendo conflitos entre os moradores da região e as mineradoras que se instalaram na Serra dos Pirineus, em razão da poluição das águas do Rio das Almas, que abastecia a localidade.

Os indícios apontam que essa realidade atravessou o século. No documento "Dossiê do Parque Estadual dos Pirineus" (s.d.) consta que o Poder Executivo do Estado de Goiás sancionou a Lei no 10.321, de 20 de dezembro de 1987, referente à criação da unidade de conservação que abrangia "a área do Pico dos Pirineus, suas serras e encostas".

Em 1995, quando técnicos da agência ambiental, à época, intensificaram as articulações para a sua implantação, encontraram obstáculos, em razão de conflitos entre mineradores da região e a sociedade civil organizada de Pirenópolis, bem como com alguns proprietários e moradores do território do parque.

Apenas em 15 de outubro de 1997, dez anos depois de sancionada a Lei, foi editado o Decreto no 4.830/1997 para regulamentação e delimitação da área de 2.833 ha, declarando-a de utilidade pública para fins de desapropriação. O Dossiê prescreve ainda que, "inexplicavelmente, mais da metade da superfície era constituída de áreas particulares já estruturadas formalmente como Unidades de Conservação." Segundo exposto, o Instituto do Meio Ambiente (Ibama) havia reconhecido parte da área como Reserva Particular do Patrimônio Natural (RPPN). Consta, também, ressalva de que todas as nascentes e fontes de água abastecedoras de Pirenópolis não fossem incluídas na área demarcada.

Em síntese, conquanto se apresentassem favoráveis às ações de preservação ambiental, proprietários de áreas menores tentaram estruturar RPPNs na região, mas tiveram seus processos arquivados no Ibama a pedido da Fundação Estadual do Meio Ambiente da época. Outras propostas de modelos associativos de preservação tentaram abrir caminho complementar à intervenção estatal, mas foram recusadas pelo referido órgão ambiental e, depois de manifesta a intenção do Estado em promover desapropriações na Região dos Pirineus, existente formalmente pelo Decreto desde 1987, os proprietários das terras se movimentaram e não mediram esforços para coibirem essa ação do poder público. Argumentavam que os inúmeros parques criados no país, em face da escassez de

Caminhos de Geografia Uberlândia $\quad$ v. 20, n. $72 \quad$ Dez/2019 $\quad$ p. 202-216 Página 209


recursos públicos, foram transformados em "terras de ninguém" e a "natureza agredida com maior intensidade após a constituição das mencionadas unidades de conservação".

Depois de vários interregnos, em 1995, o órgão ambiental anunciou que a propriedade, e outras vizinhas, cujos processos de criação de RPPN tramitavam no lbama, seriam desapropriadas com o aval favorável do próprio instituto, que enviou técnicos à região para delimitar a área do parque.

Em carta elaborada em 20 de dezembro de 1995 pelo Sr. Pompeu Christovam de Pina (11.06.193410.12.2014), morador de Pirenópolis, advogado, vereador e historiador (SECIMA, 1995), encaminhada ao bispo Dom Manoel Pestana Filho, da Diocese de Anápolis (GO), foi apontado que, com a criação do Parque Estadual dos Pirineus, em 1987, os proprietários da região esperaram oito anos para a delimitação e desapropriação por parte do Poder Executivo e sofreram "toda sorte de prejuízos pela desvalorização da área para compra e venda, bem como no investimento nas propriedades".

$\mathrm{Na}$ opinião do morador, os estudos técnicos para delimitação do território do parque foram "superficiais e protecionistas", fato comprovado pelo mapeamento do território delimitado, tendo como limite a Rodovia BR-070, não abrangendo as nascentes do rio Corumbá. O traçado geográfico ficou "em Zig e Zag", "protegendo determinados proprietários e atendendo a interesses políticos, sem critérios que justificassem o parâmetro utilizado". Além disso, os estudos não compreenderam as cabeceiras do "Córrego da Barriguda", cujo manancial abastecia a cidade de Pirenópolis; excluíram também as Cachoeiras Abade, Lázaro, Ribeirão do Inferno e outras (SECIMA, 1995). Essas informações foram corroboradas pelos gestores e servidores da Secima que trabalharam no processo de criação do parque à época e pelos proprietários que tiveram suas propriedades desapropriadas.

O processo de regularização fundiária foi igualmente controverso. Em relatório produzido pelo grupo de trabalho instituído pelo órgão ambiental à época, concluiu-se que a maior parte das terras não possuía valor para fins agropecuários, com baixo potencial econômico, composto por solos tipo cambissolos, resistentes à atuação mecânica, considerados inadequados ao uso agrícola. Haveria também restrições naturais impostas pelas condições de relevo e, assim, a vocação estaria limitada à formação de pastagens. Por outro lado, em virtude da localização em região com intenso fluxo turístico, haveria expressiva valorização. Sendo assim, em razão da indefinição na atribuição dos valores, houve polêmicas em relação aos preços atribuídos às terras, sendo que dois proprietários ainda mantêm, atualmente, processos judiciais contestando os valores já pagos.

Esse contexto evidencia o panorama problemático e conflituoso que envolveu a criação do parque. Como demonstrado em Sancho (2016), por exemplo, tal processo foi subsidiado em uma concepção externa de proteção ambiental, concretizada "de cima para baixo" e alheia (ou pouco sensível) aos interesses e opiniões dos habitantes da região. A adoção de uma postura distanciada e pouco aberta ao diálogo por parte do Poder Executivo resultou, naquele período, na sobreposição e em conflitos abrangendo, inclusive, o exercício de territorialidades pré-existentes.

Conforme mencionado anteriormente, o Pico dos Pirineus é um dos principais atrativos do Parque Estadual dos Pirineus e o ponto mais elevado da região, com 1.385 metros de altitude, sendo composto por rochas quartizíticas, de origem sedimentar, muito antigas, datadas do período précambriano (+1 bilhão de anos), sobre as quais cresce um típico de cerrado rupestre de altitude, com alto grau de endemismo (MOURA et al., 2007).

Em 1927, foi erigida uma capela dedicada à Santíssima Trindade², originariamente de madeira, onde foi realizada a primeira missa, em 18 de junho do mesmo ano. Em 1935, um vendaval destruiu a construção e no mesmo ano foi erguida outra de alvenaria, que resiste até hoje (Figura 3). Desde então passou a ser realizada, anualmente, a "Festa do Morro", que atualmente ocorre dentro do território do Parque dos Pirineus, durante uma semana, sempre no plenilúnio de julho. O ponto máximo da festa acontece com uma procissão que sai da Igreja do Senhor do Bonfim, em Pirenópolis, percorrendo 32 quilômetros até a capela com celebração da missa, no domingo.

\begin{tabular}{|c|c|}
\hline hos de Geograf & Uberlândia \\
\hline
\end{tabular}


Figura 3 - Foto da capela no topo do Pico dos Pirineus.

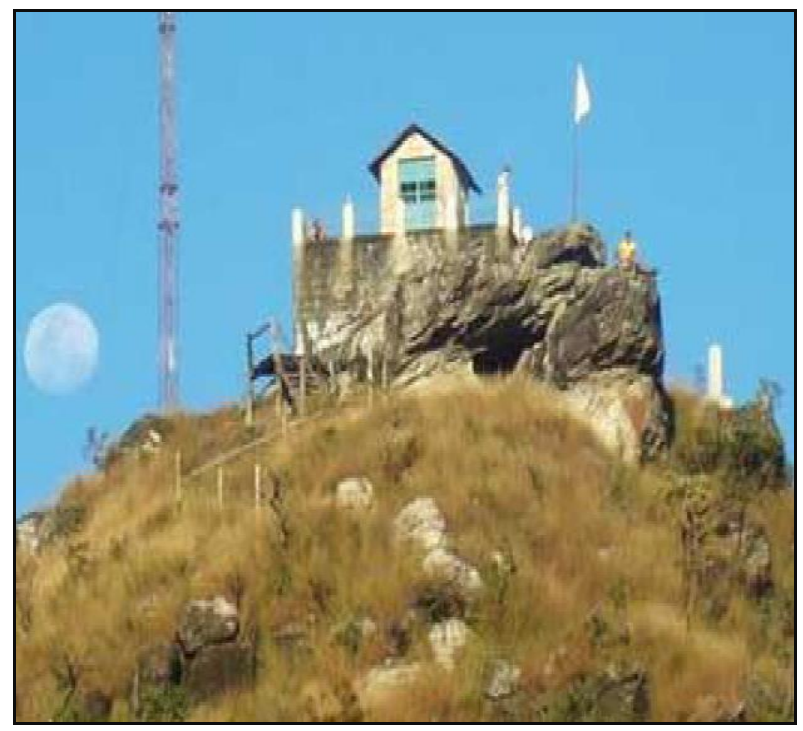

Fonte - Foto da autora, julho de 2017.

Pelo histórico de criação do parque ficou evidenciada a influência religiosa que prevaleceu e definiu a permanência da festa e dos acampamentos após a sua implantação (Figura 4). A maior área de terras (1.051 ha) era de propriedade da Igreja Católica - Diocese de Anápolis - e, no processo de regularização fundiária, os possíveis conflitos com os fiéis, a população e o governo foram dirimidos a partir da concordância pela continuidade da festa, que foi condição imposta pela proprietária. Atualmente, o evento é autorizado pela Secima, por meio de Termo de Acordo entre as partes, o qual contêm os critérios a serem cumpridos pelo coordenador (festeiro) e participantes.

Cabe descrever a festa a partir da perspectiva de seus integrantes, pessoas que acampam todos os anos no mesmo lugar, pré-fixados por genealogia. Houve relatos, nas entrevistas, de que em determinado ano alguém não conhecido montou acampamento em local já reservado para as "famílias tradicionais" de Pirenópolis. Os festeiros acionaram a polícia e retiraram as pessoas estranhas, que foram obrigadas a se deslocar para outra área.

Figura 4 - Fotos do acampamento na Festa do Morro, no Parque dos Pirineus.
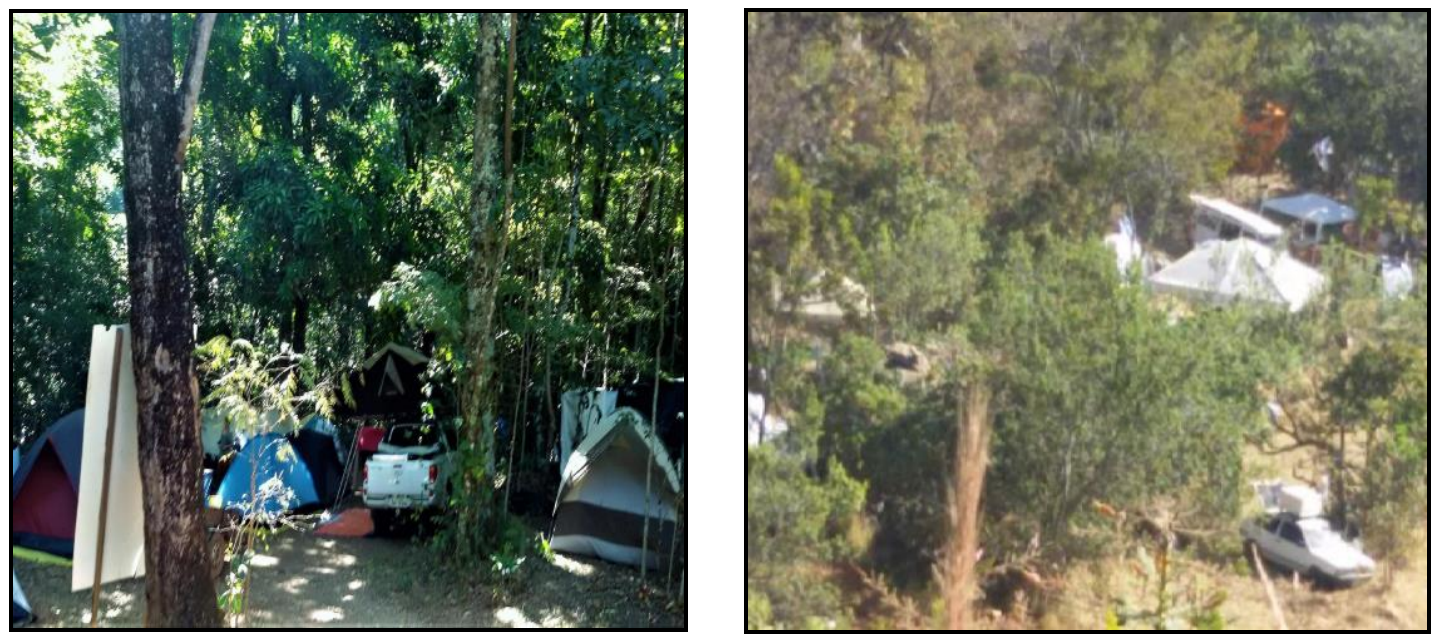

Fonte - Fotos da autora, julho de 2017.

Foi possível observar a emoção dos festeiros ao entoarem o Hino de Pirenópolis e as cantigas que relatam os costumes e as crenças da região. Pôde ser verificada, também, uma face da festa que

$\begin{array}{lllll}\text { Caminhos de Geografia } \quad \text { Uberlândia } & \text { v. 20, n. } 72 & \text { Dez/2019 } & \text { p. 202-216 Página } 211\end{array}$


envolve grupos de jovens que aproveitam as férias de julho para acampar, fazer escaladas e se divertir em contato com a natureza. Existe consenso na percepção dos participantes de que, com o passar dos anos, o acampamento teve suas origens descaracterizadas, tornando-se área de camping, com consumo de bebidas alcoólicas, música mecânica, sem qualquer relação religiosa.

Os usos do território se estendem aos proprietários do entorno. Como não existem cercas em todos os limites do parque, é comum a existência de gado no interior da unidade (Figura 5), o que tem resultado em denúncias e ações por parte do Ministério Público Estadual, acirrando os conflitos entre os proprietários e gestores, monitores do parque, bem como com os moradores que não adotam essa conduta.

Figura 5 - Fotos de gado pastoreando dentro do território do Pepi.

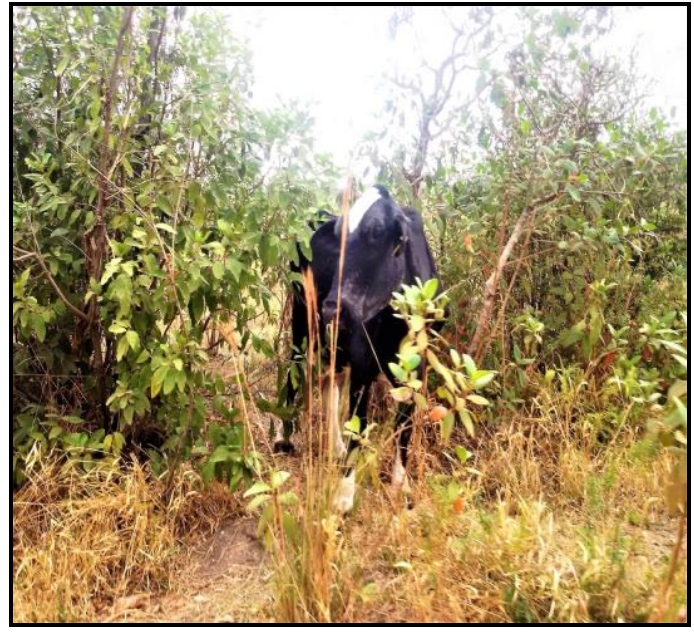

Fonte - Fotos da autora, setembro de 2016.

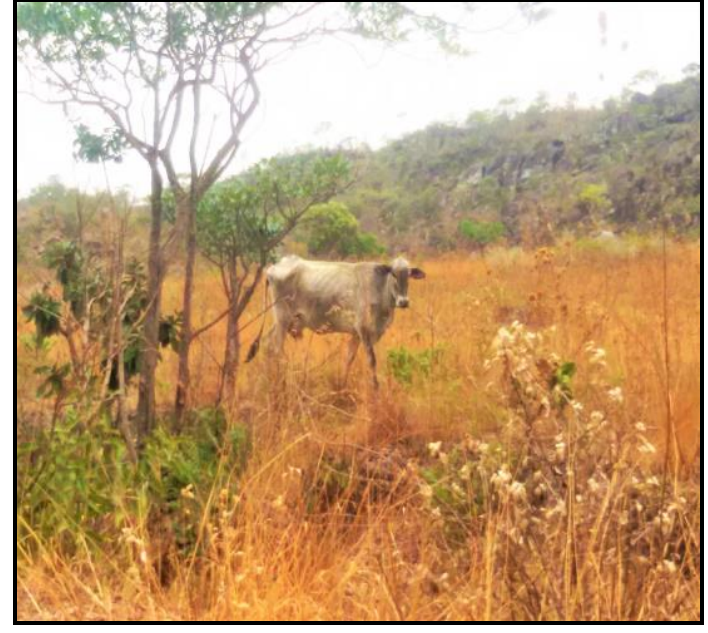

Fonte - Fotos da autora, novembro 2017.

A prática de esportes como ciclismo (Figura 6), escaladas, motocross e hayline também representa usos que não estão estabelecidos na Lei no 9.985/2000, relativa ao Sistema de Unidades de Conservação (SNUC), legislação pertinente às unidades de conservação de proteção integral. Embora sejam fatos passíveis de conflitos com a gestão do parque, existe uma relativa concordância atribuída à falta do plano de manejo, o qual deveria prescrever as normas para visitação e discriminar os possíveis locais de usos, além dos impactos decorrentes das atividades turísticas e esportivas, dentre outros.

Figura 6 - Foto de ciclista dentro dos limites do território do PEPI.

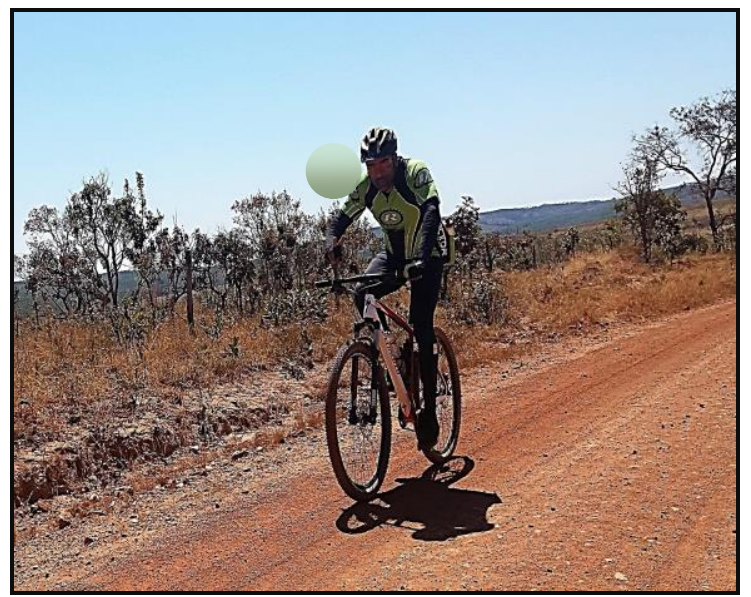

Fonte - Fotos da autora, novembro de 2017. 
Por fim, vale destacar as atividades turísticas na unidade de conservação, como o uso das cachoeiras e a realização de passeios e acampamentos (Figura 7).

Figura 7 - Fotos de prática do turismo no interior do território do Pepi.

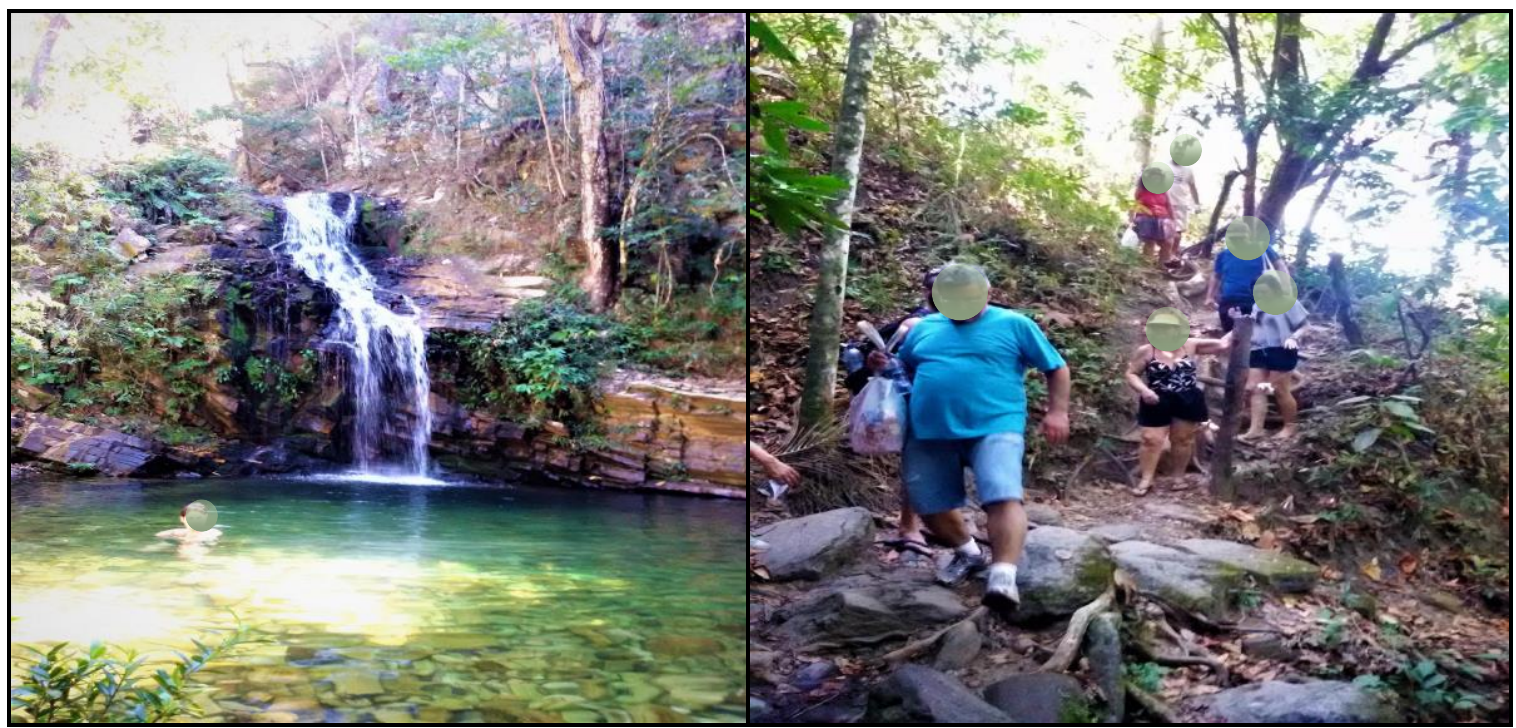

Fonte - Fotos da autora, setembro de 2016.

Uma análise contextual das situações demonstradas remete ao território como recorte espacial definido por relações de poder e de controle sobre recursos e fluxos, baseados em aspectos políticos, econômicos e culturais (HAESBAERT, 2006). Nesse enfoque, a territorialidade não envolve somente a ocupação física do espaço, compreendendo também manifestação, sentimentos e significados específicos ligados ao território, de modo que sua análise implica uma visão humana e social da realidade, não cabendo observação restrita ao caráter quantitativo.

A territorialidade envolve também significados específicos, permeada por elementos materiais e simbólico-identitários se manifestando "em todas as escalas espaciais e sociais, representando a face vivida e a face agida do poder" (RAFESTTIN, 1993, p. 162).

A análise da categoria território, na perspectiva desta pesquisa, com a identificação dos atores que se relacionam ora em conflito, ora em complementação de interesses, torna-se oportuna no processo de formação da unidade de conservação, destacando os jogos de poder dos atores sociais envolvidos. Além disso, é necessário compreender como as várias formas de concepção do território foram construídas, analisando como elas se aplicam a certa área de estudo.

A diversidade de usos do território do Parque Estadual dos Pirineus retrata a perspectiva do território usado, que remete a pensar a dinâmica territorial durante seu acontecimento, em sua materialização. Como define Silveira $(2011$, p. 3), "é o território feito e o território se fazendo", ou seja, visto como processo. Essa dinâmica acontece por meio das ações que dão vida aos objetos, isto é, o uso do território, que pode ser entendido de diversas formas, acordando com as diferentes ações humanas articuladas em sistema. É nessa ótica das ações que pode se refletir sobre a identificação empírica dos usos do território, no plural.

Cabe reforçar que tais usos acontecem em sistema, e não isoladamente, fazendo parte do movimento geral de uso do território. Como defendido por Santos (1996), os usos do território denotam modos como pelos quais se expressa a transformação da natureza pelo trabalho humano. Na formulação do autor, isso se traduz na materialidade animada pela vida social, em um conjunto de sistemas de objetos e sistemas de ações.

Steinberger e Abirached (2013) explicam e traduzem a relação sociedade-natureza na formulação do território usado aqui aplicada:

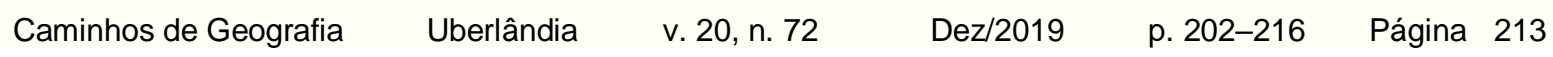




\begin{abstract}
Essa relação homem-natureza e os usos dos recursos abrangem desde práticas laborais e práticas de subsistência típicas de povos e comunidades tradicionais, com baixa intensidade sobre e os recursos naturais, até os usos habitacionais, industriais, agrícolas, minerais, turísticos e de infraestrutura, entre outros exercícios em geral pela sociedade urbano-industrial que demanda uma alta intensidade sobre a natureza e o território. (STEINBERGER; ABIRACHED, 2013, p. 136).
\end{abstract}

Nesse sentido, como as ações são múltiplas existem, de fato, múltiplos usos. Paralelamente, pode ser observada a multiplicidade de territórios e o aspecto multidimensional que envolve os conflitos socioambientais no Parque Estadual dos Pirineus.

Raffestin (1993) concebe o uso e a transformação dos recursos naturais como instrumentos (trunfos) de poder. O território, para o autor, é uma interferência de poder constante pelas práticas dos atores que o modificam a todo instante.

As relações que carregam conteúdos de poder, ou seja, intenções a serem materializadas no território, são parciais, têm uma intencionalidade, ou melhor, carregam a "vontade" de grupos que mantêm o poder e se manifestam no território através de seus interesses. A característica de cada território está carregada de diferentes intenções sobre as quais os atores expressam suas vontades no território, territorializando relações marcadas pelo poder e, dependendo do contexto histórico, de conflitos de interesses. Daí a importância da compreensão da constituição e das dinâmicas do território no âmbito das unidades de conservação.

\title{
CONSIDERAÇÕES FINAIS
}

Ante todo o cenário apresentado, em consonância com a articulação dos elementos teóricos, históricos, políticos e técnicos que compreendem a análise da gestão territorial das unidades de conservação, evidenciou-se o caráter relacional que permeia o processo de ocupação do entorno do parque e os usos do território.

Nessa perspectiva, os fatos históricos elencados expressam a territorialidade, a ligação simbólica dos grupos sociais com seu espaço, a exclusividade e a distinção entre seus ocupantes, o vivido territorial expresso por uma coletividade. A territorialidade é incorporada pela dimensão política e pelas relações econômicas e culturais, "ligada ao modo como as pessoas utilizam a terra, como elas próprias se organizam no espaço e como dão significado ao lugar" (HASBAERT, 2004, p. 3).

A partir da análise sistematizada, foi possível identificar diversos territórios, com usos diferenciados. O território dos festeiros, com apropriação física e simbólica a cada ano, os territórios dos escaladores, dos ciclistas, e dos proprietários de gado, com uso disperso e ao mesmo tempo localizado e contínuo, são situações que retratam e influenciam a dinâmica e a configuração territorial do Pepi.

Foram identificados, também, os conflitos associados a esses usos - existentes desde a criação do parque -, envolvendo, além dos demais atores, o próprio Estado, representado pelos gestores e servidores da Secima, que estão constantemente em conduta de enfrentamento e celebração de acordos, indicando, dentre outros, a vulnerabilidade no alcance da finalidade legal da UC.

O Sistema de Unidades de Conservação (Snuc), com orientações e normas de restrição, influencia na dinâmica do uso do território, abrangendo debates e conflitos socioambientais, o que retrata o caráter político da temática. Nesse contexto, compreendendo simultaneamente e de modo indissociável ações sociais e recursos naturais, podem-se reconhecer os diversos usos no Parque Estadual dos Pirineus, denotando os diferentes interesses que se materializam no território.

Considera-se, então, que a configuração da gestão territorial do Parque Estadual dos Pireneus, na formulação estabelecida, alcança os contornos do campo emblemático que envolve a gestão de áreas protegidas e os resultados das políticas públicas correlatas, como sistemas de objetos e sistemas de ações imbricados, de forma indissociável, na perspectiva do território usado.

\section{AGRADECIMENTOS}

Os autores agradecem à Secretaria do Meio Ambiente, Recursos Hídricos, Infraestrutura, Cidades e Assuntos Metropolitanos (Secima) pela autorização de acesso aos limites do Parque Estadual dos Pirineus.

Caminhos de Geografia Uberlândia $\quad$ v. 20, n. $72 \quad$ Dez/2019 $\quad$ p. 202-216 Página 214




\section{REFERÊNCIAS}

ACSELRAD, H. As práticas espaciais e o campo dos conflitos ambientais. In: ACSELRAD, H. (Org.). Conflitos ambientais no Brasil. Rio de Janeiro: Relume Dumará, 2004. 294 p.

ANDRADE, E. A. Avaliação da eficácia da política de gestão das Unidades de Conservação do estado de Goiás. 2012. Dissertação (Mestrado em Sociedade, Tecnologia e Meio Ambiente) Centro Universitário de Anápolis - UniEvangélica, Anápolis, 2012. Disponível em: <http://www.unievangelica.edu.br/files/images/Edna\%20de\%20Araujo\%20Andrade.pdf>. Acesso em: 2 ago. 2015.

BOSQUETI, L. Barros. Análise da estrutura da paisagem e fitofisionomias do Parque Estadual de Pirineus, Goiás/Brasil. Tese (Doutorado) - Escola Superior de Agricultura Luiz de Queiroz. Centro de Energia Nuclear na Agricultura: Piracicaba, 2008. Disponível em: <http://www.teses.usp.br/teses/disponiveis/91/91131/tde-25112008-103815/pt-br.php>. Acesso em: 9 nov. 2014.

BRASIL. Presidência da República. Casa Civil. Subchefia para Assuntos Jurídicos. Lei no 9.985, de 18 de julho de 2000. Regulamenta o art. 225, § 1ํ, incisos I, II, III e VII da Constituição Federal, institui o Sistema Nacional de Unidades de Conservação da Natureza e dá outras providências. Disponível em: <http//www.planalto.gov.br/ccivil_03/LEIS/L9985.htm>. Acesso em: 11 nov. 2011.

CATAIA, Márcio Antônio. Território político: fundamento e fundação do Estado. Sociedade \& natureza (UFU, online), v. 23, p. 115-125, 2011. Disponível em: <http://www.scielo.br/scielo.php?pid=S198245132011000100010\&script=sci_abstract\&tlng=es>. Acesso em: 4 jun. 2015. https://doi.org/10.1590/S1982-45132011000100010

CATTANEO, D. S. Identidade territorial em unidades de conservação: ponto de apoio para uma análise epistemológica da questão ambiental. Dissertação (Mestrado em Geografia) - Universidade Federal do Rio Grande do Sul, Porto Alegre, Rio Grande do Sul, 2004. Disponível em: <https://www.lume.ufrgs.br/bitstream/handle/10183/5796/000520720.pdf? sequence=1 >. Acesso em: 2 mar. 2011.

GOIÁS. Avaliação Rápida da Priorização da Gestão - RAPPAM em Unidades de Conservação, Estaduais em Goiás. Goiânia: SEMARH, 2014. Disponível em: <http://secima.go.gov.br/pos/ver/19693/publicacoes-ucs>. Acesso em: 3 mar. 2015.

GOIÁS. Decreto no 4.830, de 15 de outubro de 1997. Estabelece a área e os limites do Parque Estadual dos Pirineus, localizado nos Municípios de Pirenópolis, Cocalzinho e Corumbá de Goiás, e dá outras providências. Disponível em: <http://www.gabinetecivil.goias.gov.br/pagina_decretos.php?id=2192>. Acesso em: 2 jan. 2011.

GUIVANT, J. S. Sustentabilidade e métodos participativos: os riscos dos pressupostos realistas. In: Congresso Mundial da International Sociological Association, Brisbane, Austrália, julho de 2002.

GUIVANT, J.; SCHEIBE, L. F.; ASSMANN, S. J. (Org). Desenvolvimento e conflitos no ambiente rural. Florianópolis: Insular, 2005.

HAESBAERT, R. Desterritorialização: entre as redes e os aglomerados de exclusão. In: CASTRO, I. E. et al. (Org.). Geografia: conceitos e temas. 2. ed. Rio de Janeiro: Bertrand Brasil, 2010. p. 165205.

HAESBAERT, R. O mito da desterritorialização: do "fim dos territórios" à multiterritorialidade. Rio de Janeiro: Bertrand Brasil, 2009. p. 396. https://doi.org/10.22409/GEOgraphia2004.v6i12.a13478

HAESBAERT, R. Territórios alternativos. 2. ed. São Paulo: Contexto, 2006.

HAESBAERT, R. Território e multiterritorialidade: um debate. GEOgrafia, v. 17, 2007. Disponível em: <http://www.geographia.uff.br/index.php/geographia/article/viewFile/213/205>. Acesso em: 4 jun. 2015.

HAESBAERT, R. Dos múltiplos territórios á multiterritorialidade. In: Heidrich, Álvaro et al. (Org.). A emergência da multiterritorialidade: a ressignificação da relação do humano com o espaço. $1^{\underline{a}}$ ed. Porto Alegre (RS): Editora da ULBRA e Editora da UFRGS, 2008. p. 19-36.

HERCULANO, S. Redesenhando o debate sobre justiça ambiental: produção teórica, breve acervo de casos e criação da rede brasileira de justiça ambiental. Desenvolvimento e Meio Ambiente, Curitiba, v. 5, p. 143-152, jan.jun. 2002. Disponível em:

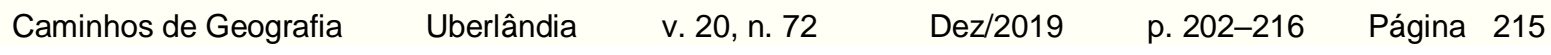


$<$ http://ojs.c3sl.ufpr.br/ojs/index.php/made/article/view/22124>. Acesso em: 12 jan. 2015. https://doi.org/10.5380/dma.v5i0.22124

LEFEBVRE, H. La production de l'espace. Paris: Anthropos, 1986.

LEFF, E. Saber Ambiental. Sostenibilidad, racionalidad, complejidad, poder. México: Siglo XXI, 1998. Disponível em: <https://monoskop.org/images/f/fc/Lefebvre_Henri_O_direito_a_cidade.pdf>. Acesso em: 3 dez. 2015.

LITTLE, P. Os conflitos socioambientais: um campo de estudo e de ação política. In: BURZSTYN, M. (Org.). A difícil sustentabilidade: política energética e conflitos ambientais. Rio de Janeiro: Garamond, 2001. p. 111-115.

MORAES, A. C. R. Território na Geografia de Milton Santos. São Paulo: Annablume, 2013. 126 p.

MOURA, I. O. et al. Fitossociologia da comunidade lenhosa de uma área de Cerrado Rupestre no Parque Estadual dos Pirineus, Pirenópolis, Goiás. Revista de Biologia Neotropical, v. 4, n. 2, p. 83100, 2007. https://doi.org/10.5216/rbn.v4i2.5208

RAFFESTIN, C. Por uma geografia do poder. São Paulo: Ática, 1993. 266 p.

RICHARDSON, R. J. Pesquisa social: métodos e técnicas. São Paulo: Atlas, 1999.

$\mathrm{SANCHO}$, A. Des-ordenamento territorial e unidades de conservação. 2016. 460 f. Tese (Doutorado em Geografia) - Programa de Pós-Graduação do Departamento de Geografia, Universidade Federal de Minas Gerais, Belo Horizonte, 2016.

SANTOS, M. A natureza do espaço: técnica e tempo, razão e emoção. 4. ed. São Paulo: Hucitec, 1996.

SANTOS, M. Por uma outra globalização: do pensamento único à consciência universal. 10. ed. Rio de Janeiro: Record, 2008.

SANTOS, M.; SILVEIRA, M. L. O Brasil: território e sociedade no início do século XXI. São Paulo: Record, 2001. 474 p.

SECIMA - Secretaria do Meio Ambiente, Recursos Hídricos, Infraestrutura, Cidades e Assuntos Metropolitanos. Carta de Cristovam Pompeu de Pina. Trata da criação do Parque Estadual dos Pirineus. Pirenópolis, 1995.

SILVEIRA, M. L.O Brasil: território e sociedade no início do século 21- a história de um livro. ACTA Geográfica, Boa Vista, Ed. Esp. Cidades na Amazônia Brasileira, 2011. Disponível em: https://revista.ufrr.br/actageo/article/view/556. Acesso em: 04 mar. 2015. https://doi.org/10.5654/actageo2011.0001.0011

SOUZA, M. L. de. Sobre o espaço: território, autonomia e desenvolvimento In: CASTRO, I. E. de; GOMES, P. C. C.; CORRÊA, R. L. (Org.). Geografia: conceitos e temas. Rio de Janeiro: Bertrand Brasil, 2010 p. 77-116.

STEINBERGER, M.; AMADO, T. O espaço urbano no zoneamento ecológico-econômico: esboço metodológico. In: STEINBERGER, M. (Org.). Território, Estado e políticas públicas espaciais. Brasília: Ler Editora, 2013. p. 151-185.

STEINBERGER, M.; ABIRACHED, C. A. Politica ambiental: do Estado do uso da natureza e do território. In.: STEINBERGER, M. Território, Estado e políticas públicas espaciais. Brasília: Ler Editora, 2013. 328 p.

VARGAS, G. M. Conflitos sociais e socioambientais: proposta de um marco teórico e metodológico. Sociedade \& Natureza, São Paulo, v. 19, n. 2, p. 191-203, 2007. Disponível em: <http://www.seer.ufu.br/index.php/sociedadenatureza/article/view/9284>. Acesso em: 2 fev. 2014. https://doi.org/10.1590/S1982-45132007000200012

Recebido em: 18/06/2018

Aceito para publicação em: 26/11/2019

$\begin{array}{llllll}\text { Caminhos de Geografia } & \text { Uberlândia } & \text { v. 20, n. } 72 & \text { Dez/2019 } & \text { p. 202-216 Página } 216\end{array}$

